\title{
Hydrophilic Surface Coating of Flow Diverters: A Possible Way to Omit Dual Platelet Aggregation Inhibition
}

\author{
Ansgar Berlis ${ }^{1}$
}

Experience with flow diverters has been collected since 2007. After initially overestimating the treatment options, a very good indication profile has emerged in recent years. Current studies like the PREMIER Study show excellent results of low morbidity and mortality rates, even lower than with conventional endovascular treatment [1]. The main reason for this is the possibility to differ between unequivocally indications and contraindications, as well as periprocedural blood coagulation management.

Testing on antiplatelet drug response is one of the major goals to reduce complications. Nevertheless, thromboembolic complications and in-stent thrombosis are still the most common complications, especially when flow diverters with a high proportion of material inside the vessel are used. Surface-modified flow diverters with reduced thrombogenicity were introduced to minimize the rate of complications. The recently introduced Pipeline Flex Embolization Device with Shield Technology (Pipeline Shield) is the third generation of Pipeline flow-diverter devices using covalent phosphorylcholine attachment to the implant wires [2,3]. Recently published data demonstrates that complication and occlusion rates of Pipeline Shield do not differ from other flow diverters. Although lower thrombogenicity has been demonstrated in in vitro studies, the clinical studies have all been performed with dual platelet inhibition [2]. There is a lack of information about antiplatelet monotherapy, which has not yet been

Ansgar Berlis

ansgar.berlis@uk-augsburg.de

1 Klinik für Diagnostische und Interventionelle Radiologie und Neuroradiologie, Universitätsklinikum Augsburg,

Stenglinstr. 2, 86156 Augsburg, Germany investigated in clinical settings. Dual platelet inhibition has an increased bleeding rate. Utilization of monotherapy on patients with subarachnoid hemorrhage (SAH) or with concomitant anticoagulant therapy would be desirable.

One possible way to reduce thrombogenicity is the new hydrophilic-coated flow diverter (p48-HPC) (phenox $\mathrm{GmbH}$, Germany). An effective surface modification of the flow diverter would make it dispense with double antiplatelet treatment in special situations. The results of this animal study are very interesting and promising [4]. Although this is a rather small animal study, the authors could nicely show that hydrophilic coating alone reduced clot burden at areas where the flow diverter crossed side branches by a factor of 100 and when Aspirin was added by a factor of 1000 compared to the non-coated control. The combination of both factors (hydrophilic coating and Aspirin) reduced the surface thrombus load virtually to zero, and additional Clopidogrel did not have any effect. This was proven by high-frequency optical coherence tomography, which has a spatial resolution of $10 \mu \mathrm{m}$. Although these results are very promising, we need to keep in mind that they derive from a small series including just 3 animals. In addition, the authors tested only the acute phase $20 \mathrm{~min}$ after insertion of the flow diverters. Although initial clinical experience with the p48-HPC flow diverter using single antiplatelet therapy has been already achieved [5], more extensive experimental and well-structured clinical studies are required to prove the concept of hydrophilic coating and single antiplatelet therapy in the usage of intracranial flow diverters. 


\section{References}

1. Hanel RA, et al. Prospective study on embolization of intracranial aneurysms with the pipeline device: the PREMIER study 1 year results. J Neurointervent Surg. 2020;12:62-6.

2. Atasoy D, et al. Outcome study of the pipeline embolization device with shield technology in unruptured aneurysms (PEDSU). AJNR Am J Neuroradiol. 2019;40:2094-101.

3. Girdhar G, et al. Thrombogenicity of pipeline, pipeline shield, derivo and P64 flow diverters in an in vitro human blood loop model. eNeuroloicalSci. 2019;14:77-84.
4. King R, Langan ET, Ughi GJ, et al. Acute thrombus burden on coated flow diverters assessed by high frequency optical coherence tomography. Cardiovasc Intervent Radiol. 2020. https://doi.org/10. 1007/s00270-020-02482-w.

5. Aguilar-Perez M, Hellstern V, AlMatter M, et al. The p48 flow modulation device with hydrophilic polymer coating (HPC) for the treatment of acutely ruptured aneurysms: early clinical experience using single antiplatelet therapy. Cardiovasc Intervent Radiol. 2020. https://doi.org/10.1007/s00270-020-02418-4 (Epub ahead of print). 